Research Paper

\title{
Newly-synthesized chalcones-inhibition of adherence and biofilm formation of methicillin-resistant Staphylococcus aureus
}

\author{
Dragana D. Bozic ${ }^{1}$, Marina Milenkovic ${ }^{1}$, Branka Ivkovic ${ }^{2}$, Ivana Cirkovic ${ }^{3}$ \\ ${ }^{1}$ Department of Microbiology and Immunology, University of Belgrade-Faculty of Pharmacy, \\ Belgrade, Serbia. \\ ${ }^{2}$ Department of Pharmaceutical Chemistry, University of Belgrade-Faculty of Pharmacy, \\ Belgrade, Serbia. \\ ${ }^{3}$ Institute of Microbiology and Immunology, School of Medicine, University of Belgrade, \\ Belgrade, Serbia.
}

Submitted: July 4, 2012; Approved: September 9, 2013.

\begin{abstract}
Biofilm formation and adherence of bacteria to host tissue are one of the most important virulence factors of methicillin-resistant strains of Staphylococcus aureus (MRSA). The number of resistant strains is seriously increasing during the past years and bacteria have become resistant, not only to methicillin, but also to other commonly used antistaphylococcal antibiotics. There is a great need for discovering a novel antimicrobial agent for the treatment of staphylococcal infections. One of the most promising groups of compounds appears to be chalcones. In present study we evaluated the in vitro effect of three newly synthesized chalcones: 1,3- Bis-(2-hydroxy-phenyl)-propenone, 3-(3Hydroxy-phenyl)-1-(2-hydroxy-phenyl)-propenone and 3-(4-Hydroxy-phenyl)-1-(2-hydroxyphenyl)-propenone on glycocalyx production, biofilm formation and adherence to human fibronectin of clinical isolates and laboratory control strain of MRSA (ATCC 43300). Subinhibitory concentrations of the tested compounds reduced the production of glycocalyx, biofilm formation and adherence to human fibronectin of all MRSA strains. Inhibition of biofilm formation was dose dependent and the most effective was 1,3- Bis-(2-hydroxy-phenyl)-propenone. In our study we demonstrated that three newly-synthesized chalcones exhibited significant effect on adherence and biofilm formation of MRSA strains. Chalcones may be considered as promising new antimicrobial agents that can be used for prevention of staphylococcal infections or as adjunct to antibiotics in conventional therapy.
\end{abstract}

Key words: chalcones, glycocalyx, biofilms, MRSA.

\section{Introduction}

Staphylococcus aureus is one of the most frequent pathogen that cause broad spectrum of nosocomial and community-acquired infections. At the beginning, with the development of beta-lactamase resistant penicillins, such as methicillin in the early 1960 s, there has been a great improvement in the treatment of staphylococcal infections. Nevertheless, the first methicillin-resistant strains of Staphylococcus aureus (i.e. MRSA) emerged during the first year of methicillin usage, and their number is continuously increasing in passed several decades making MRSA infections a serious clinical and therapeutical problem (Garau et al., 2009).

Among various virulence factors of S. aureus responsible for different purulent or toxic infections, biofilm formation has been recognized as the most important for prolonged and recurrent infections with these bacteria. Biofilm is a complex multilayer structure that forms on the polymer surfaces of implanted medical devices. The two step process of biofilm formation consists of the adherence of bacteria to the surface followed by the aggregation of 
bacteria and formation of multilayer structure. Bacteria in biofilm are connected with amorphous slimy material named polysaccharide intercellular adhesin (Gotz, 2004) that acts as specific cell glue making this layer very adherent and more tolerant to both environmental factors (Rode et al., 2007) and antimicrobial agents (Heiby et al., 2010). The slimy material is not a true capsule since it is loosely bound to the staphylococcal surface and it is believed that it plays essential role in bacterial contamination of medical devices. Staphylococci do not form biofilms only on artificial implants. It has been recognized that they also possess the ability to bind to the different components of extracellular matrix and colonize the surface of mammalian host cells (Gotz, 2002). This specific adherence is not mediated by the production of glycocalyx, but rather by adhesins like fibronectin-binding proteins $\mathrm{A}$ and $\mathrm{B}$, collagen-binding protein Cna, fibrinogen-binding proteins, clumping factor A and B and others (Foster and Höök, 1998; Van Belkum et al., 2002). Beside the advanced epidemiological measures developed for minimizing the spread of the resistant strains in environment and between humans, there is a great need for a discovery of a novel antimicrobial compounds that will improve the treatment of MRSA infections.

Chalcones belong to a group of flavonoides, naturally occurring compounds biosynthesized in various plant species, fruits and vegetables. Chemical structure of these compounds is made of two aryl rings linked by a $\alpha, \beta$-unsaturated ketone. So far it has been proved that different chalcones possess a broad spectrum of potent biological activities: antibacterial, antiviral, antifungal, antiangiogenic, anticancer, antiproliferative and anti-inflammatory (Nowakowska, 2007; Mojzis et al., 2008; Kontogiorgios et al., 2008; Boumendjel et al., 2009; Batovska and Todorova, 2010). Beside chalcones isolated from natural sources, many chalcones and their analogues can be obtained by the methods of classical and combinatorial synthesis.

Since the first step of the colonization and host-cell invasion is staphylococcal adhesion to the components of the extracellular matrix and cell surface (Foster and Höök, 1998; Sinha and Fraunholz, 2010) our interest was to investigate the influence of the three newly-synthesized chalcones on biofilm formation, slime production and binding to fibronectin of 30 different MRSA strains. The antiadhesive activity of 1,3- Bis-(2-hydroxy-phenyl)-propenone, 3-(3-Hydroxy-phenyl)-1-(2-hydroxy-phenyl)-propenone and 3-(4-Hydroxy-phenyl)-1-(2-hydroxy-phenyl)propenone against MRSA strains was investigated for the first time.

\section{Methods}

\section{Bacterial strains and culture media}

The influence of chalcones on adhesive properties of staphylococci was tested using 30 clinical isolates of MRSA obtained from blood (3), wound (11), sputum (3), endotracheal tube (3), tracheostoma (2), abdominal drain (2), nose (2), skin (1), urine (1), urethra (1) and external auditory canal (1). Identification of the isolates and methicillin resistance were determined by VITEK 2 test cards GP and AST-P580 (bioMérieux, France) and confirmed by PCR for nuc (Brakstad et al., 1992) and mecA (Bignardi et al., 1996) genes. One laboratory control strain of methicillin-resistant S. aureus ATCC 43300 (KWIK-STIK ${ }^{\mathrm{TM}}$, Microbiologics, USA) was used as positive control. Clinical isolates of MRSA were stored at $-70^{\circ} \mathrm{C}$ in brain heart infusion broth (BHI; Lab M Limited, UK) with the addition of $10 \%$ sterile glycerol. Prior to experiment, bacteria were defrosted, inoculated on tryptic soy agar (TSA; Lab M Limited) and cultivated in aerobic conditions for 18-24 h at $35^{\circ} \mathrm{C}$.

\section{Chalcones}

The effect of the newly synthesized chalcones 1,3Bis-(2-hydroxy-phenyl)-propenone (further referred as $\mathrm{O}$ -

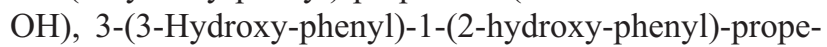
none (further referred as $\mathrm{M}-\mathrm{OH}$ ) and 3-(4-Hydroxyphenyl)-1-(2-hydroxy-phenyl)-propenone (further referred as $\mathrm{P}-\mathrm{OH}$ ) on adhesive properties of MRSA was investigated for the first time. All three tested compounds were obtained from the Department of Pharmaceutical Chemistry, University of Belgrade-Faculty of Pharmacy, Serbia. Chalcones were prepared through base catalyzed ClaisenSchmidt condensation of ortho, metha or para hydroxy substituted benzaldehydes with 2-hydroxy acetophenones. Synthesized compounds were characterized by IR, NMR and mass spectrometry. The purity of the compounds was checked using HPLC and TLC methods. The structures of investigated chalcones are presented in Table 1.

Subinhibitory concentrations of the tested compounds previously determined by broth microdilution test (0.5 x minimal inhibitory concentration, MIC) were used for the detection of the effect of chalcones on glycocalyx production, biofilm formation and adherence to human

Table 1 - The chemical structures of the tested chalcones: 1,3- Bis-(2-hydroxy-phenyl)-propenone (further referred as $\mathrm{O}-\mathrm{OH})$, 3-(3-Hydroxyphenyl)-1-(2-hydroxy-phenyl)-propenone (further referred as $\mathrm{M}-\mathrm{OH})$ and 3-(4-Hydroxy-phenyl)-1-(2-hydroxy-phenyl)-propenone (further referred as $\mathrm{P}-\mathrm{OH})$.

\begin{tabular}{|c|c|c|c|}
\hline & & & \\
\hline Compound & $\mathrm{R} 1$ & $\mathrm{R} 2$ & $\mathrm{R} 3$ \\
\hline $\mathrm{O}-\mathrm{OH}$ & $-\mathrm{OH}$ & $-\mathrm{H}$ & $-\mathrm{H}$ \\
\hline $\mathrm{M}-\mathrm{OH}$ & $-\mathrm{H}$ & $-\mathrm{OH}$ & $-\mathrm{H}$ \\
\hline $\mathrm{P}-\mathrm{OH}$ & $-\mathrm{H}$ & $-\mathrm{H}$ & $-\mathrm{OH}$ \\
\hline
\end{tabular}


fibronectin. Prior to experiments, chalcones were dissolved in sterile dimethyl sulphoxide (DMSO; Sigma-Aldrich, USA) to a stock solution of $1000 \mu \mathrm{g} / \mathrm{mL}$ and subsequently diluted to the desired concentrations with medium.

\section{Production of glycocalyx}

Glycocalyx production was detected by Congo-red agar method (Freeman et al., 1989) and Christensen method (Christensen et al., 1982). For detection of glycocalyx production in the presence of chalcones, we used subinhibitory concentrations of chalcones $(50 \mu \mathrm{g} / \mathrm{mL}$ for $\mathrm{M}-\mathrm{OH}$ and $\mathrm{P}-\mathrm{OH}$ and $25 \mu \mathrm{g} / \mathrm{mL}$ for $\mathrm{O}-\mathrm{OH}$ ) prepared in tryptone soy broth (TSB; Lab M Limited). Inoculum of bacteria ( $0.5 \mathrm{McF}$ arland) was incubated at $35^{\circ} \mathrm{C}$ in aerobic conditions in $2 \mathrm{~mL}$ of TSB-chalcone dilution in 24-well plates (Sarstedt, USA) for Congo red agar method (CRA) or in test tubes for Christensen method. Positive controls of each strain were incubated under the same conditions without presence of chalcones. Each test was repeated three times.

\section{Congo red agar method}

Bacterial strains were incubated with chalcones (for $24 \mathrm{~h}$ or $48 \mathrm{~h}$ ) and then bacteria were inoculated on plates containing $20 \mathrm{~mL}$ of brain heart infusion agar (Himedia, India) supplemented with 5\% saccharose and $0.08 \%$ Congo red (Fisher scientific, UK). Plates were incubated on $35^{\circ} \mathrm{C}$ in aerobic conditions for $24 \mathrm{~h}$ after which results were interpreted according to following criteria: black colonies with dry crystalline consistency indicated for the positive result (slime production), pink colonies were usually present at non-slime producers and darkening of the colonies with the absence of the dry-crystalline morphology was categorized as indeterminate result (Freeman et al., 1989: Cree et al., 1995).

\section{Christensen method}

After $48 \mathrm{~h}$ of cultivation of the bacteria in the static conditions, test tubes were gently decanted and $1 \mathrm{~mL}$ of $0.4 \%$ aqueous solution of trypan blue (BDH chemicals Ltd, UK) was added to each tube. Tubes were slowly rotated in order to achieve uniform staining of the remnant slime and tubes were dried upside down. Bacterial strain was categorized as a slime producer if colored precipitate was observed at the bottom of the test tube (Christensen et al., 1982; Freeman et al., 1989).

\section{Biofilm assay}

Biofilm formation was tested in 96-well microtiter plates according to Stepanovic et al. (2007). One colony of the overnight cultures of bacterial strains was diluted in saline in order to adjust the turbidity of the bacterial suspension to 0.5 McFarland standard (approximately $\left.10^{8} \mathrm{cfu} / \mathrm{mL}\right)$.
Serial dilutions of chalcones $(12.5,25$ and $50 \mu \mathrm{g} / \mathrm{mL}$ for $\mathrm{M}-\mathrm{OH}$ and $\mathrm{P}-\mathrm{OH}$ and $6.25,12.5$ and $25 \mu \mathrm{g} / \mathrm{mL}$ for $\mathrm{O}-\mathrm{OH}$ ) were prepared in fresh TSB (supplemented with additional 1\% glucose) or BHI (supplemented with additional $2 \%$ glucose and 2\% saccharose) according to Knobloch et al. (2002) and $180 \mu \mathrm{L}$ of each dilution was poured in triplicates into microtiter plate. A $20 \mu \mathrm{L}$ of previously prepared bacterial suspension was added to each well. Positive controls of each strain (bacteria in medium without presence of chalcones) were incubated under the same conditions. Negative control for each plate was medium solely. After $24 \mathrm{~h}$ of incubation at $35^{\circ} \mathrm{C}$ in aerobic conditions plates were decanted and rinsed gently three times with $300 \mu \mathrm{L}$ of sterile phosphate-buffered saline (PBS; pH 7.2). After air drying plates were fixed with $150 \mu \mathrm{L}$ methanol per well for $20 \mathrm{~min}$, dried and stained with $150 \mu \mathrm{L}$ (per well) of $2 \%$ crystal violet (Himedia) for $15 \mathrm{~min}$. Unbounded dye was rinsed with water and dye bounded to the cell wall of adherent bacteria was released with $150 \mu \mathrm{L}$ of $96 \%$ ethanol/well for $20 \mathrm{~min}$. Optical density (OD) was measured at $570 \mathrm{~nm}$ using a microtiter plate reader (ICN Flow Titertek Multiscan Plus) following the calculation of the results according to Stepanovic et al. (2000). Each assay was repeated three times on three consecutive days. Since all tests were performed in triplicate and repeated three times, the average OD values were calculated for all tested strains and negative controls. To calculate the category of biofilm production, we determined the cut-off optical density (ODc) as three standard deviations above the mean OD of the negative control. According to the obtained results all tested strains were divided into four groups:

$\mathrm{OD} \leq \mathrm{ODc}$ - category 0 (non-adherent strain, no biofilm producer) ducer)

ODc $<$ OD $\leq 2 x O D c$ - category 1 (weak biofilm pro$2 \mathrm{xODc}<\mathrm{OD} \leq 4 \mathrm{xODc}$ - category 2 (moderate biofilm producer)

4xODc $<$ OD - category 3 (strong biofilm producer)

\section{Microtiter plate adhesion assay}

Adhesion of tested bacterial strains to human fibronectin was evaluated according to Peacock et al. (2000). All tested strains of staphylococci were preincubated for $24 \mathrm{~h}$ and $48 \mathrm{~h}$ in the presence of subinhibitory concentrations of chalcones in 24 well plates as previously described in the section of production of glycocalyx. Each isolate had its own positive control (bacteria cultivated solely in medium at the same laboratory conditions).

Polysorp microtiter plates (NUNC, Denmark) were coated for $1 \mathrm{~h}$ at $37^{\circ} \mathrm{C}$ with $25 \mu \mathrm{g} / \mathrm{mL}$ of human fibronectin (Serva, Germany). After overnight blockage of the remaining sites at $4{ }^{\circ} \mathrm{C}$ with $200 \mu \mathrm{L}$ of $2 \%$ bovine serum albumine (Sigma-Aldrich) in PBS, plates were washed three times with PBS and inoculum of $1 \times 10^{8}$ bacteria in PBS/well was 
added in triplicates to each well. Plates were incubated $1 \mathrm{~h}$ at $37{ }^{\circ} \mathrm{C}$, rinsed three times with PBS, fixed with $2 \%$ glutaraldehyde (TCI Europe) in PBS for $1 \mathrm{~h}$ and stained with crystal violet for $5 \mathrm{~min}$. After rinsing with water and air drying, the absorbance was measured at $\mathrm{OD}_{405}$. Two triplicates of PBS without bacteria served as a negative control for each plate. After calculation of the results, absorbance values were expressed as the percentage of the absorbance of the positive control. Each assay was repeated three times.

\section{Statistical analysis}

The data obtained in this study were analyzed in SPSS statistical program (PASW statistics 18.0 version) using Student's $t$-test.

\section{Results}

\section{Glycocalyx production of MRSA strains}

The results obtained from Congo red agar method showed that $25 / 31(80.6 \%)$ of strains (including control MRSA strain ATCC 43300) formed black colonies indicating for positive production of glycocalyx, while 6/31 $(19.4 \%)$ of strains had indeterminate result since they formed dark pink-red colonies without dry crystalline morphology. Production of glycocalyx observed by Christensen method confirmed slime production for 21/31 (67.7\%) of strains while $4 / 31(12.9 \%)$ of strains had discrepancy with CRA method. After precultivation in the presence of chalcones, all three tested compounds exerted significant inhibitory effect on the slime production detected by both methods. O-OH chalcone was the most effective since $25 / 31(80.6 \%)$ of strains reduced the glycocalyx production, following $\mathrm{P}-\mathrm{OH}$ with $22 / 31(71 \%)$ and $\mathrm{M}-\mathrm{OH}$ with 20/31 (64.5\%) respectively.

\section{Biofilm production of MRSA strains}

Biofilm formation was investigated for 30 clinical strains and one control strain of MRSA ATCC 43300 in three independent experiments during three consecutive days. According to these results, all tested strains showed ability to form biofilm as following: $1 / 31$ strain $(3.2 \%)$ was low biofilm producer, 15/31 strains (48.4\%) showed moderate biofilm production and $15 / 31$ strains $(48.4 \%)$ were strong biofilm producers. Category of biofilm production of MRSA strains isolated from different specimens is presented in Table 2 . The ability of biofilm production was observed after $24 \mathrm{~h}$ and $48 \mathrm{~h}$ with no statistically significant difference between results ( $p>0.05$, data not shown). Concerning this, we decided to estimate production of biofilm after $24 \mathrm{~h}$ of incubation in the presence of chalcones.

Inhibition of biofilm production was dose dependent with most of the strains showing no production or low biofilm production at highest concentration of chalcones
Table 2 - Category of biofilm production of MRSA strains.

\begin{tabular}{lcccc}
\hline \multirow{2}{*}{ Specimen } & $\begin{array}{c}\mathrm{N}^{\circ} \text { of } \\
\text { strains }\end{array}$ & \multicolumn{2}{c}{ Category of biofilm production } \\
\cline { 3 - 5 } & & 1 & 2 & 3 \\
\hline blood & 3 & - & 3 & - \\
wound swab & 11 & - & 5 & 6 \\
endotracheal tube swab & 3 & - & 1 & 2 \\
sputum & 3 & 1 & 1 & 1 \\
tracheostomal swab & 2 & - & 1 & 1 \\
abdominal drain swab & 2 & - & 1 & 1 \\
nose swab & 2 & - & - & 2 \\
skin swab & 1 & - & - & 1 \\
urine & 1 & - & 1 & - \\
urethral swab & 1 & - & 1 & - \\
external auditory canal & 1 & - & - & 1 \\
swab & & & & \\
ATCC 43300 & 1 & - & 1 & - \\
$\Sigma$ & 31 & 1 & 15 & 15 \\
\hline
\end{tabular}

1-weak biofilm producer, 2-moderate biofilm producer, 3-strong biofilm producer.

applied (Table 3). The most significant suppression of the biofilm production exhibited $\mathrm{O}-\mathrm{OH}$ chalcone since all of the strains with moderate/strong biofilm production decreased biofilm formation in the presence of the lowest concentration $(6.25 \mu \mathrm{g} / \mathrm{mL})$ of the tested compound. Only 1 strain (belonging to a group of weak biofilm producers) reached the level of the positive control. P-OH and $\mathrm{M}-\mathrm{OH}$ chalcones applied at the lowest concentration $(12.5 \mu \mathrm{g} / \mathrm{mL})$ had a slightly weaker effect compared to $\mathrm{O}-\mathrm{OH}$ with $13 / 31$ $(42 \%)$ of strains reaching the level of the positive control for $\mathrm{P}-\mathrm{OH}$ and $18 / 31$ of strains (58\%) for $\mathrm{M}-\mathrm{OH}$ respectively (Table 3 ).

\section{Binding of MRSA strains to human fibronectin}

All tested MRSA strains had similar capability of binding to immobilized fibronectin. After $24 \mathrm{~h}$ of incubation in the presence of chalcones we detected statistically significant decrease in fibronectin binding compared to untreated controls as following: 22/31 (71\%) of strains reduced binding to fibronectin after cultivation in the presence of $\mathrm{O}-\mathrm{OH}$ chalcone, $24 / 31(77.4 \%)$ of strains in the presence of $\mathrm{M}-\mathrm{OH}$ and $27 / 31$ (87\%) \% in the presence of $\mathrm{P}-\mathrm{OH}$ respectively (Table 4). Strains that were primary resistant to the effect of chalcones during the $24 \mathrm{~h}$ incubation significantly reduced fibronectin-binding ability after prolonged incubation of bacteria for $48 \mathrm{~h}$ in the presence of the tested compounds ( $p<0.05$, data not shown). There was no statistically significant difference in binding to human fibronectin between MRSA strains isolated from respiratory tract, wound, blood and other specimens after $24 / 48 \mathrm{~h}$ of incubation in the presence of the tested chalcones $(\mathrm{p}>0.05$, data not shown). 
Table 3 - Production of biofilm after 24 h cultivation of MRSA strains in the presence of O-OH, M-OH and P-OH chalcones.

\begin{tabular}{|c|c|c|c|c|c|c|c|c|c|c|}
\hline \multirow{3}{*}{$\begin{array}{l}\text { Biofilm production of con- } \\
\text { trol strain ( } n^{\circ} \text { of strains) }\end{array}$} & \multicolumn{10}{|c|}{ Biofilm production after precultivation in the presence of chalcones } \\
\hline & \multirow[b]{2}{*}{ Category } & \multicolumn{3}{|c|}{$\mathrm{O}-\mathrm{OH}(\mu \mathrm{g} / \mathrm{mL})$} & \multicolumn{3}{|c|}{$\mathrm{M}-\mathrm{OH}(\mu \mathrm{g} / \mathrm{mL})$} & \multicolumn{3}{|c|}{$\mathrm{P}-\mathrm{OH}(\mu \mathrm{g} / \mathrm{mL})$} \\
\hline & & 6.25 & 12.5 & 25 & 12.5 & 25 & 50 & 12.5 & 25 & 50 \\
\hline \multirow[t]{4}{*}{ Weak $(1 / 31)$} & 0 & - & $1 / 1$ & $1 / 1$ & - & $1 / 1$ & $1 / 1$ & - & - & - \\
\hline & 1 & $1 / 1$ & - & - & $1 / 1$ & - & - & $1 / 1$ & $1 / 1$ & $1 / 1$ \\
\hline & 2 & - & - & - & - & - & - & - & - & - \\
\hline & 3 & - & - & - & - & - & - & - & - & - \\
\hline \multirow[t]{4}{*}{ Moderate $(15 / 31)$} & 0 & $6 / 15$ & $11 / 15$ & $11 / 15$ & - & - & $5 / 15$ & - & - & $2 / 15$ \\
\hline & 1 & $9 / 15$ & $4 / 15$ & $4 / 15$ & $5 / 15$ & $14 / 15$ & $10 / 15$ & $10 / 15$ & $14 / 15$ & $13 / 15$ \\
\hline & 2 & - & - & - & $10 / 15$ & $1 / 15$ & - & $5 / 15$ & $1 / 15$ & - \\
\hline & 3 & - & - & - & - & - & - & - & - & - \\
\hline \multirow[t]{4}{*}{ Strong $(15 / 31)$} & 0 & $2 / 15$ & $6 / 15$ & $9 / 15$ & - & - & - & - & - & - \\
\hline & 1 & $13 / 15$ & $9 / 15$ & $6 / 15$ & - & $3 / 15$ & $11 / 15$ & - & $5 / 15$ & $10 / 15$ \\
\hline & 2 & - & - & - & $8 / 15$ & $10 / 15$ & $4 / 15$ & $8 / 15$ & $8 / 15$ & $3 / 15$ \\
\hline & 3 & - & - & - & $7 / 15$ & $2 / 15$ & - & $7 / 15$ & $2 / 15$ & $2 / 15$ \\
\hline
\end{tabular}

0-no biofilm production, 1-weak biofilm producer, 2-moderate biofilm producer, 3-strong biofilm producer.

\section{Discussion}

Antimicrobial activity of chalcones is well documented and dependent on their chemical structure (Nielsen et al., 2005; Nowakowska, 2007; Batovska and Todorova, 2010). Our preliminary results showed that all three newly synthesized compounds have inhibitory activity against MRSA with MIC values ranging from $50-75 \mu \mathrm{g} / \mathrm{mL}$ for $\mathrm{O}-\mathrm{OH}$ chalcone and $75-125 \mu \mathrm{g} / \mathrm{mL}$ for $\mathrm{M}-\mathrm{OH}$ and $\mathrm{P}-\mathrm{OH}$ chalcone (data not shown). Other authors reported similar activity of various chalcones against MRSA. Hatano et al. (2000) and Fukai et al. (2002) found that Licochalcone A isolated from liquorice (rooth and rhizome of Glycyrrhiza spp.) exerted antibacterial activity against MRSA with MIC values ranging from $6.25-16 \mu \mathrm{g} / \mathrm{mL}$ depending on the strain of microorganism. Besides naturally occurring chalcones, it has been reported that synthesized chalcones also possess strong anti-MRSA activity. Bowman et al. (2007) identified 5 antibacterial compounds out of 198 investigated chalcones among which one chalcone exerted stronger anti-MRSA activity with MIC value $3.0 \mu \mathrm{M}$ compared to MIC value $8.0 \mu \mathrm{M}$ of linezolid. Trihidroxychalcones, as newly synthesized 2.4.2'-trihidroxy-5'-methylchalcone investigated by Sato et al. (1996) exerted antistaphylococcal activity against 19 MRSA isolates with complete growth inhibition at $50 \mu \mathrm{g} / \mathrm{mL}$ and one strain at $25 \mu \mathrm{g} / \mathrm{mL}$.

In our study we found that incubation of MRSA strains in the presence of subinhibitory concentrations of chalcones significantly reduced the production of glycocalyx detected by CRA and Christensen method. Discrepancy between these two methods was low and in accordance with the results of other authors (Freeman et al., 1989; Cree et al., 1995). CRA and Christhensen methods are qualitative and not $100 \%$ reliable since Christhensen method shows low success for detection of weak slime production (Christensen et al., 1982) and results obtained from CRA method can often be misinterpreted due to variation in black pigmentation of colonies or decrease of the black color with the time (Freeman et al., 1989; Mariana et al., 2009). To evade the subjectivity of the beholder, we performed a quantitative microtiter-plate biofilm assay and confirmed the biofilm production in all tested strains of MRSA. Inhibition of biofilm formation in the presence of chalcones was dose dependent and most of the strains did not reach the level of the untreated controls at the lowest concentration of chalcones applied. Fibronectin-binding of MRSA strains was also diminished after precultivation in the presence of the tested chalcones indicating that bacteria reduced their ability to adhere to a host tissue as well as to plastic polymer surfaces.

Since the survival of bacteria, biofilm production and adherence to fibronectin-binding proteins are unrelated events we can presume that some specific chemical feature of the tested compounds influences some general processes in bacterial cells. Although antimicrobial activity of chalcones cannot be assigned to a presence of merely one functional group, several studies reported the same structural patterns of different investigated compounds. The most significant structural characteristics responsible for antistaphylococcal activity of the chalcones are presence of the $\mathrm{OH}$ group and lipophilicity of the molecule (Nowakowska, 2007). Alcaraz et al. (2000) confirmed that chalcones with highest anti-MRSA activity are open chain flavonoids whose basic structure includes two aromatic rings bound by an $\alpha, \beta$-unsaturated carbonyl group. Presence of the $\mathrm{OH}$ group at 2' or 2'.4' position of B ring is essential for 
Table 4 - Fibronectin binding of MRSA strains after $24 \mathrm{~h}$ cultivation in the presence of chalcones.

\begin{tabular}{|c|c|c|c|c|}
\hline $\mathrm{N}^{0}$ of strain & O-OH 24 h $25 \mu \mathrm{g} / \mathrm{mL}$ & M-OH 24 h $50 \mu \mathrm{g} / \mathrm{mL}$ & P-OH 24 h $50 \mu \mathrm{g} / \mathrm{mL}$ & Control $24 \mathrm{~h}$ \\
\hline 3 & $66.7 \pm 2.7 *$ & $71.7 \pm 12.4$ & $66.0 \pm 1.3 *$ & $100.0 \pm 8.0$ \\
\hline 4 & $73.7 \pm 1.1 * *$ & $63.7 \pm 5.2 * *$ & $77.9 \pm 8.6$ & $100.0 \pm 3.8$ \\
\hline 5 & $69.4 \pm 0.6 * *$ & $60.1 \pm 1.3 * *$ & $55.1 \pm 2.8 * *$ & $100.0 \pm 3.5$ \\
\hline 6 & $68.0 \pm 4.0 *$ & $80.3 \pm 4.6 *$ & $64.1 \pm 1.4 * *$ & $100.0 \pm 4.1$ \\
\hline 7 & $55.1 \pm 4.0 *$ & $63.5 \pm 15.2$ & $55.6 \pm 0.4 *$ & $100.0 \pm 10.0$ \\
\hline 8 & $63.1 \pm 8.0 *$ & $65.5 \pm 0.5 *$ & $59.5 \pm 0.6 * *$ & $100.0 \pm 5.1$ \\
\hline 10 & $56.4 \pm 1.5 *$ & $75.2 \pm 11.4$ * & $66.7 \pm 2.6^{*}$ & $100.0 \pm 7.7$ \\
\hline 12 & $54.3 \pm 1.5$ & $61.1 \pm 3.9$ & $62.7 \pm 7.6$ & $100.0 \pm 12.3$ \\
\hline 13 & $71.3 \pm 8.0 *$ & $65.5 \pm 6.3 *$ & $58.6 \pm 1.4 * *$ & $100.0 \pm 3.7$ \\
\hline 14 & $68.2 \pm 8.6$ & $58.9 \pm 0.7 *$ & $52.2 \pm 1.4 *$ & $100.0 \pm 12.1$ \\
\hline 15 & $66.0 \pm 5.5 *$ & $66.7 \pm 1.4 * *$ & $79.6 \pm 5.7 *$ & $100.0 \pm 4.1$ \\
\hline 16 & $56.8 \pm 11.1 *$ & $50.9 \pm 1.4 * * *$ & $49.4 \pm 2.8 * * *$ & $100.0 \pm 1.0$ \\
\hline 17 & $57.4 \pm 7.3 * *$ & $68.0 \pm 13.5$ & $63.3 \pm 14.5 *$ & $100.0 \pm 0.8$ \\
\hline 18 & $52.2 \pm 1.4 *$ & $56.8 \pm 12.9$ & $49.6 \pm 0.3 *$ & $100.0 \pm 9.9$ \\
\hline 19 & $31.2 \pm 8.3 *$ & $27.5 \pm 3.1 *$ & $30.6 \pm 14.1 *$ & $100.0 \pm 11.7$ \\
\hline 20 & $59.3 \pm 9.7 *$ & $39.4 \pm 4.4 * *$ & $40.7 \pm 5.7 * *$ & $100.0 \pm 3.4$ \\
\hline 21 & $73.7 \pm 7.3 *$ & $55.9 \pm 6.4 * *$ & $53.3 \pm 3.4 * *$ & $100.0 \pm 1.3$ \\
\hline 24 & $62.8 \pm 1.5 * *$ & $59.5 \pm 9.2 * *$ & $57.0 \pm 3.2 * *$ & $100.0 \pm 1.4$ \\
\hline 25 & $38.2 \pm 4.3 *$ & $43.5 \pm 1.3 *$ & $42.4 \pm 2.6 *$ & $100.0 \pm 13.9$ \\
\hline 26 & $35.3 \pm 8.0$ & $36.3 \pm 1.3$ & $39.7 \pm 15.4$ & $100.0 \pm 17.7$ \\
\hline 27 & $48.5 \pm 6.1$ & $55.8 \pm 8.2$ & $45.6 \pm 10.5$ & $100.0 \pm 12.4$ \\
\hline 28 & $65.1 \pm 4.6 * *$ & $55.6 \pm 0.6 * *$ & $55.1 \pm 6.7 * *$ & $100.0 \pm 1.1$ \\
\hline 29 & $59.7 \pm 11.6$ & $42.9 \pm 6.7 *$ & $43.4 \pm 0.8 *$ & $100.0 \pm 14.7$ \\
\hline 34 & $64.7 \pm 11.4$ & $44.2 \pm 5.1 * *$ & $44.6 \pm 3.8 * *$ & $100.0 \pm 1.7$ \\
\hline 35 & $59.3 \pm 14.3$ & $52.0 \pm 6.3 * *$ & $58.9 \pm 2.2 * *$ & $100.0 \pm 2.9$ \\
\hline 47 & $56.7 \pm 12.9$ & $44.6 \pm 1.2 * *$ & $44.9 \pm 7.0 * *$ & $100.0 \pm 0.8$ \\
\hline 50 & $48.3 \pm 7.6 *$ & $51.2 \pm 11.2 *$ & $41.6 \pm 3.8 *$ & $100.0 \pm 10.2$ \\
\hline 53 & $64.6 \pm 12.9$ & $45.3 \pm 2.6 * *$ & $48.2 \pm 8.6 * *$ & $100.0 \pm 4.4$ \\
\hline 58 & $58.9 \pm 2.3 * *$ & $52.2 \pm 2.6 * *$ & $50.7 \pm 1.3 * *$ & $100.0 \pm 2.0$ \\
\hline 89 & $63.9 \pm 1.0 * *$ & $61.6 \pm 4.2 * *$ & $49.2 \pm 4.0 * *$ & $100.0 \pm 1.0$ \\
\hline ATCC 43300 & $63.4 \pm 5.5 * *$ & $63.0 \pm 10.2 * *$ & $47.5 \pm 5.4 * *$ & $100.0 \pm 1.9$ \\
\hline
\end{tabular}

Results are expressed as the percentage of the absorbance of the positive control (presented as $100 \% \pm \mathrm{SD}$ ); ${ }^{*} \mathrm{p}<0.05 ; * * \mathrm{p}<0.01 ; * * * \mathrm{p}<0.001$.

anti-MRSA activity of these compounds with MIC values ranging from $12.7-38.7 \mu \mathrm{g} / \mathrm{mL}$ (Alcaraz et al., 2000). Kromann et al. (2004) showed that the free hydroxyl group in 4 ' position of ring $\mathrm{B}$ is necessary for the antistaphylococcal activity of licochalcone A analogues.

Results of this research are in agreement with findings of Alcaraz et al. (2000) and Kromann et al. (2004). We can propose that anti-MRSA activity of the $\mathrm{O}-\mathrm{OH}, \mathrm{M}-\mathrm{OH}$ and $\mathrm{P}-\mathrm{OH}$ chalcones is due to presence of the carbonyl group and functional $\mathrm{OH}$ group in the 2', 3' or 4' position of $\mathrm{B}$ ring.

Precise mechanism of antimicrobial effect of different chalcones is still unknown. Other pharmacological compounds with carbonyl group exert their action through direct interaction with some enzymes usually through hydrogen bonds. Ohemeng et al. (1993) screened 14 flavonoids of varying structure for inhibitory activity against DNA gyrase and found that enzyme inhibition was limited to those compounds with B-ring hydroxylation. Not only do certain flavonoids inhibit DNA synthesis but they can also affect RNA synthesis in S. aureus (Mori et al., 1987). Other enzymes involved in metabolism of macromolecules (DNA, RNA, carbohydrates and proteins) can also be affected in S. aureus. Haraguchi et al. (1998) demonstrated that licochalcones may be interfering with energy metabo- 
lism by inhibition of NADH-cytochrome $c$ reductase, reducing the energy required for active uptake of various metabolites and for biosynthesis of macromolecules. Since antimicrobial activity and enzyme inhibition are not always in correlation, Ohemeng et al. (1993) suggested that other mechanisms can be involved.

In conclusion, results obtained in this study suggest that tested compounds exibited strong effect on biofilm formation, glycocalyx production and binding to human fibronectin of MRSA strains. This effect was dose dependent and chalcone with hydroxyl group at 2' position of B ring was the most effective one. Due to high antistaphylococcal activity of evaluated chalcones and their effect on virulence factors of MRSA strains, presented results provide useful information for further investigations of possible application of chalcones as promising new antimicrobial agents, for prevention of bacterial adherence to plastic polymer surfaces or for treatment of staphylococcal infections in combination with conventional anti-MRSA therapy.

\section{Acknowledgments}

Funding: The work of Dragana D. Bozic and Ivana Cirkovic was supported by the Ministry of Science, Republic of Serbia (project grant no. 175039).

Conflicts of interests: None declared. Ethical approval: Not required.

\section{References}

Alcaraz LE, Blanco SE, Puig ON, Tomas F, Ferretti FH (2000) Antibacterial activity of flavonoids against methicillin-resistant Staphylococcus aureus strains. J Theor Biol 205:231-240.

Batovska DI, Todorova IT (2010) Trends in utilization of the pharmacological potential of chalcones. Curr Clin Pharmacol 5:1-29.

Bignardi GE, Woodford N, Chapman A, Johnson AP, Speller DCE (1996) Detection of the mecA and phenotypic detection of resistance in Staphylococcus aureus isolates with borderline or low-level methicillin resistance. J Antimicrob Chemoth 37:53-63.

Boumendjel A, Ronot X, Boutonnat J (2009) Chalcones derivatives acting as cell cycle blockers: potential anti cancer drugs? Curr Drug Targets 10:363-371.

Bowman MD, O’Neill JC, Stringer JR, Blackwell HE (2007) Rapid identification of antibacterial agents effective against Staphylococcus aureus using small-molecule microarrays. Chem Biol 14:351-357.

Brakstad OG, Aabakk K, Maeland JA (1992) Detection of Staphylococcus aureus by polymerase chain reaction amplification of the nuc gene. J Clin Microbiol 30:1654-1660.

Christensen GD, Simpson WA, Bisno AL, Beachey EH (1982) Adherence of slime-producing strains of Staphylococcus epidermidis to smooth surfaces. Infect Immun 37:318-326.

Cree RGA, Phillips I, Noble WC (1995) Adherence characteristics of coagulase-negative staphylococci isolated from patients with infective endocarditis. J Med Microbiol 43:161168.
Foster TJ, Höök M (1998) Surface protein adhesins of Staphylococcus aureus. Trends Microbiol 6:484-488.

Freeman DJ, Falkiner FR, Keane CT (1989) New method for detecting slime production by coagulase negative staphylococci. J Clin Pathol 42:872-874.

Fukai T, Marumo A, Kaitou K, Kanda T, Terada S, Nomura T (2002) Antimicrobial activity of licorice flavonoids against methicillin-resistant Staphylococcus aureus. Fitoterapia 73:536-539.

Garau J, Bouza E, Chastre J, Gudiol F, Harbarth S (2009) Management of methicillin-resistant Staphylococcus aureus infections. Clin Microbiol Infect 15:125-136.

Götz F (2002) Staphylococcus and biofilms. Mol Microbiol 43:1367-1378.

Götz F (2004) Staphylococci in colonization and disease: prospective targets for drugs and vaccines. Curr Opin Microbiol 7:477-487.

Haraguchi H, Tanimoto K, Tamura Y, Miyutani K, Kinoshita T (1998) Mode of antibacterial action of retrochalcones from Glycyrrhiza infiltrata. Phytochemistry 48:125-129.

Hatano T, Shintani Y, Aga Y, Shiota S, Tsuchiya T, Yoshida T (2000) Phenolic Constituents of Licorice. VIII. Structures of Glicophenone and Glicoisoflavanone, and Effects of Licorice Phenolics on Methicillin-Resistant Staphylococcus aureus. Chem Pharm Bull 48:1286-1292.

Heiby N, Bjarnsholt T, Givskov M, Molin S, Ciofu O (2010) Antibiotic resistance of bacterial biofilms. Int $\mathrm{J}$ Antimicrob Agents 35:322-332.

Knobloch JK, Horstkotte MA, Rhode H, Mack D (2002) Evaluation of different detection methods of biofilm formation in Staphylococcus aureus. Med Microbiol Immunol 191:101106.

Kontogiorgis C, Mantzanidou M, Hadjipavlou-Litina D (2008) Chalcones and their potential role in inflammation. Mini Rev Med Chem 8:1224-1242.

Kromann H, Larsen M, Boesen T, Schønning K, Nielsen SF (2004) Synthesis of prenylated benzaldehydes and their use in the synthesis of analogues of licochalcone A. Eur J Med Chem 39:993-1000.

Mariana NS, Salman SA, Neela V, Zamberi S (2009) Evaluation of modified Congo red agar for detection of biofilm produced by clinical isolates of methicillin-resistance Staphylococcus aureus. Afr J Microbiol Res 3:330-338.

Mojzis J, Varinska L, Mojzisova G, Kostova I, Mirossay L (2008) Antiangiogenic effects of flavonoids and chalcones. Pharmacol Res 57:259-265.

Mori A, Nishino C, Enoki N, Tawata S (1987) Antibacterial activity and mode of action of plant flavonoids against Proteus vulgaris and Staphylococcus aureus. Phytochemistry 26:2231-2234.

Nielsen SF, Larsen M, Boesen T, Schønning K, Kromann H (2005) Cationic chalcone antibiotics. Design, synthesis, and mechanism of action. J Med Chem 48:2667-2677.

Nowakowska Z (2007) A review of anti-infective and antiinflammatory chalcones. Eur J Med Chem 42:125-137.

Ohemeng KA, Schwender CF, Fu KP, Barrett JF (1993) DNA gyrase inhibitory and antibacterial activity of some flavones (1). Bioorg Med Chem Lett 3:225-230.

Peacock SJ, Day NPJ, Thomas MG, Berendt AR, Foster TJ (2000) Clinical isolates of Staphylococcus aureus exibit diversity in 
fnb genes and adhesion to human fibronectin. J Infect 41:23-31.

Rode TM, Langsurd S, Holck A, Moretro T (2007) Different patterns of biofilm formation in Staphylococcus aureus under food-related stress conditions. I J Food Microbiol 116:372-383.

Sato M, Tsuchiya H, Miyazaki T, Fujiwara S, Yamaguchi R, Kureshiro H, Iinuma M (1996) Antibacterial activity of hydroxychalcone against methicillin-resistant Staphylococcus aureus. Int J Antimicrob Agents 6:227-231.

Sinha B, Fraunholz M (2010) Staphylococcus aureus host cell invasion and post-invasion events. Int $\mathrm{J}$ Med Microbiol 300:170-175.

Stepanovic S, Vukovic D, Dakic I, Savic B, Svabic-Vlahovic M (2000) A modified microtiter-plate test for quantification of staphylococcal biofilm formation. J Microbiol Methods 40:175-179.

Stepanovic S, Vukovic D, Hola V, Di Bonaventura G, Djukic S, Cirkovic I, Ruzicka F (2007) Quantification of biofilm microtiter plates: overview of testing conditions and practical recommendations for assessment of biofilm production by staphylococci. APMIS 115:891-899.

Van Belkum A, Kools-Sijmons M, Verbrugh H (2002) Attachment of Staphylococcus aureus to eucaryotic cells and experimental pitfalls in staphylococcal adherence assays-a critical appraisal. J Microbiol Methods 48:19-42.

All the content of the journal, except where otherwise noted, is licensed under a Creative Commons License CC BY-NC. 